\title{
Conceitos gengráficos aplicados à análise econômica ambiental
}

\section{Geographic concepts applied to environmental economic analysis}

\author{
Thiago Avelar Chaves * \\ Osmar Abílio de Carvalho Júnior** \\ Roberto Arnaldo Trancoso Gomes*** \\ Jorge Enoch Furquim Werneck Lima**** \\ Renato Fontes Guimarães**
}

\section{Resumo:}

O presente trabalho visa demonstrar a aplicação dos conceitos geográficos de espaço e paisagem na economia ambiental. $O$ trabalho se divide em três partes: (a) discussão dos conceitos de espaço geográfico e paisagem; (b) diferenciação entre as duas principais vertentes da economia ambiental; e (c) análise dos conceitos geográficos aplicados para a economia ambiental. A estimativa do valor econômico de um recurso natural é mais eficiente quando a sua dimensão espacial e temporal é considerada, evitando, assim, uma análise restrita ao benefício econômico e considerando sua integração ao espaço geográfico e paisagem. Assim, esta abordagem salienta a importância da incorporação de novas variáveis aos modelos econômicos existentes.

\section{Abstract:}

The present paper aims to demonstrate the applications of space and landscape concepts in environmental economics. The paper is divided in three parts: (a) discussion of the geographical concepts (space and landscape); (b) differentiation between the two main approaches of environmental economics; and (c) discussion of geographical concepts applied to environmental economics. The estimate of the economic value of a natural resource is most efficient when the spatial and temporal dimension is considered, thus avoiding, an analysis restricted to the economic benefit considering its integration to geographic space and landscape. Thus, this approach emphasizes the importance of incorporating new variables to existing economic models.
* Doutor em Geografia pela UNB. Consultor na área de geoprocessamento e meio ambiente.

** Doutor em Geologia. Professor da Universidade de Brasília.

*** Doutor em Geografia. Professor da Universidade de Brasília.

**** Doutor em Tecnologia Ambiental e Recursos Hídricos pela UNB. Pesquisador em Hidrologia da Embrapa Cerrados

Palavras-chave:

Economia ambiental, Sistemas Ambientais, Paisagem

Key-Words:

Environmental economy, Environmental systems, Landscape 


\section{INTRODUÇÃO}

A totalidade do espaço geográfico é formada por diversas instâncias, entre elas, a paisagem. Uma característica fundamental a todas as paisagens é que estas estão sempre em transformação. Com o aumento da pressão sobre os recursos da paisagem, tais como: terra, água, minérios, entre outros, estas transformações se intensificam (HEIDE, et al., 2008).

Assim, existe a necessidade de aperfeiçoar as demandas sobre o uso da paisagem e de seus diversos elementos. O foco das políticas de planejamento, em especial, as de desenvolvimento rural (difundidas desde meados da década de 1980), enfatiza as características da paisagem, incluindo a fauna e a flora (WHATERN, 1986). Nesse sentido, os efeitos das mudanças ambientais na paisagem e sua influência na economia devem ser levados em conta para estabelecer uma medida para a realocação dos recursos escassos (DRAKE, 1999). Um exemplo disso é o fato de que, em nível localizado, a geração, manipulação e descarte de resíduos e efluentes recebem atenção de diversos países por meio de políticas defensivas, envolvendo, cada vez mais recursos econômicos e financeiros (MUELLER, 2007). Outro exemplo que pode ser citado são os impactos causados pela degradação do solo e a retirada de seus nutrientes na agricultura, que provoca sérios problemas para a economia de diversos países. Tal degradação dos recursos da paisagem ameaça o crescimento econômico e o bem-estar da população, afetando principalmente os indivíduos de baixa renda (BARBIER, 1998).

De acordo com Veiga e Ehlers (2003), a promoção de práticas conservacionistas é um vetor de dinamização de áreas rurais permitindo alavancar o crescimento econômico ao invés de prejudicá-lo. Bennet (1929) já apontava para esta questão ao chamar a atenção para os custos provocados pela erosão do solo na agricultura. Estes custos são provocados pela interferência das atividades econômicas na paisagem, que consistem nos fluxos de matéria, energia, e informação dos estoques de capital natural ${ }^{1}$ que combinam o capital manufaturado e humano para produzir um estado de bem-estar social (CONSTANZA et al., 1997). Os serviços ambientais fornecem o suporte necessário para a manutenção das funções da paisagem (ORTIZ, 2003).

Porém, estes serviços ambientais não são incorporados completamente ao mercado, assim como não são adequadamente quantificados em termos de serviços eco- nômicos e capital manufaturado, recebendo pouco peso no contexto das decisões políticas, vindo a comprometer a sustentabilidade do crescimento econômico (CONSTANZA et al., 1997, FISHER et al., 2009). Além disso, os autores consideram importante a estimativa de valores marginais dos serviços ambientais, estimando a taxa de alteração do valor entre o ambiente natural e o alterado.

Para analisar tais mudanças, não se deve basear apenas nos aspectos econômicos dos serviços ambientais, mas também na dinâmica ambiental dos diferentes ecossistemas para não incorrer no erro de inferir que deve-se substituir uma paisagem com maior valor econômico por outra de menor valor econômico, tal como afirma Constanza et al. (1997). As mudanças podem ser analisadas a partir de um grande leque de dados, tais como: cartas topográficas, imagens de sensoriamento remoto, dados estatísticos, entre outros. Tais análises de mudanças devem considerar o estado em que a paisagem se encontra como ponto de referência (BENDER et al., 2005).

Neste contexto, o presente trabalho visa demonstrar a aplicação dos conceitos geográficos de espaço e paisagem na economia ambiental. Assim, o trabalho se divide em três partes: primeiramente, são discutidos os conceitos de espaço geográfico e paisagem, e como esta pode ser entendida como um sistema; em seguida, é feito uma diferenciação entre as duas principais vertentes da economia ambiental - a economia ambiental neoclássica e a economia ecológica - abordando algumas técnicas de valoração ambiental; por fim, é demonstrado como os conceitos geográficos discutidos se aplicam à economia ambiental.

\section{ESPAÇO E PAISAGEM}

Ao longo da história da humanidade, a compreensão acerca do tema do espaço geográfico ${ }^{2}$ e da paisagem foi influenciada pelo desenvolvimento da filosofia, religião, política, ciência, busca pela estética, entre outros aspectos (MAXIMIANO, 2004).

Santos (1996) conduz o leitor a uma intuição epistemológica deste sistema de objetos e ações através das diversas categorias do espaço geográfico, em que, inicialmente, desenvolve um raciocínio demonstrando que este sistema é o próprio espaço geográfico em si, caracterizado por possuir intencionalidades, que criam espaço através da interação entre objetos e ações. Estas intencionalidades resultantes de eventos específicos, em que ação e objeto são inseparáveis, podem ser conceituadas como: 
O resultado de um feixe de vetores, conduzido por um processo, levando uma nova função ao meio pré-existente. Mas o evento só é identificável quando ele é percebido, isto é, se perfaz e se completa. E o evento somente se completa quando integrado ao meio. Somente aí há o evento, não antes. (...) se aquele feixe de vetores pudesse ser parado no caminho, antes de se instalar, não haveria evento. A ação não se dá sem que haja um objeto. E, quando exercida, acaba por se redefinir como ação e por redefinir o objeto. Por isso os eventos (dotados de intencionalidade) estão dotados no próprio coração da interpretação geográfica dos fenômenos sociais (SANTOS, 1996, p. 95).

Ainda segundo este autor,

a ideia de forma-conteúdo une o processo e o resultado, a função e a forma, o passado e o futuro, o objeto e o sujeito, o natural e o social (SANTOS, 1996, p. 66).

Nesse sentido, o espaço geográfico é a totalidade, ou seja, é "a especificação do todo social” (SANTOS, 1996, p. 120).

Além disso, Santos (1996) considera necessário a distinção entre Paisagem e o Espaço.

A paisagem é o conjunto de formas que, num dado momento, exprimem as heranças que representam as sucessivas relações localizadas entre homem e natureza. O espaço são essas formas mais a vida que as anima (SANTOS, 1996, p. 103).

De acordo com Martinelli e Pedrotti (2001) e Rocha (2007), que realizaram extensa revisão bibliográfica sobre o tema, a humanidade utiliza a paisagem como expressão de vivência desde seus primórdios, mas, é somente a partir de pensadores como Aristóteles, que este conceito passa a ser refletido, visualizando-o como um composto de elementos naturais e construídos.

O termo paisagem é aplicado como conceito geográfico durante a primeira metade do séc. XIX com o trabalho do naturalista Alexander Von Humbold, que se baseia na fisionomia da vegetação como critério essencial para a caracterização de uma paisagem. O conceito passa, a partir deste momento, por uma série de modificações que seguem até os dias de hoje (HOLZER, 1999; MARTINELLI e PEDROTTI, 2001; ROCHA, 2007).

Rocha (2007) coloca que, o marco para o desenvolvimento do pensamento geográfico se dá com o estabelecimento da discussão em torno das culturas. A partir das ideias de Sauer, "a paisagem é referenciada não mais apenas como uma cena contemplada por um observador, mas da percepção de diversas cenas individuais" (ROCHA, 2007, p. 24). Nesse sentido, a paisagem possui, ao mesmo tempo uma individualidade e se relaciona com outras paisagens.
Nesse sentido, Martinelli e Pedrotti (2001), dizem que as escalas temporais e espaciais são fundamentais para o discernimento de diferentes paisagens, já que: Sua adequação tem a ver com a categoria de estudo, (...) com-
patível com a resolução dos fenômenos nela enquadrados, os
quais por sua vez demandam certo tempo para a sua orga-
nização, e com a consequente manifestação espacial carac-
terística. Porém, esses fenômenos não acontecem apenas de
forma sucessiva, mas também de maneira simultânea. (...) a
categoria espacial e, concomitantemente, temporal de interes-
se estaria inserida numa sequência hierarquizada de escalas
temporo-espaciais, a qual escalonaria as ordens de grandeza,
os respectivos relacionamentos ou contradições de natureza
física, biológica ou social (...) (MARTINELLI e PEDROTTI,
2001, p.41).

Já Maximiano (2004) entende a paisagem como uma manifestação do espaço geográfico, sendo o produto das interações entre elementos de origem natural e humana, em um determinado espaço, que se organizam de maneira dinâmica, ao longo do tempo e do espaço. Tal processo resulta na formação de feições dinâmicas, diferenciadas ou repetidas, permitindo a sua classificação.

Martins et al. (2004) partem de uma abordagem multidisciplinar para apresentar a noção de que a paisagem se insere em um conjunto de sistemas e ações. Apesar de possuir uma abordagem diferenciada de Santos (1996), estes autores se aproximam das ideias deste quando afirmam que:

As imagens de ação estão se tornando mais importantes que as imagens de objeto. $\mathrm{O}$ estudo das transformações torna-se o foco das pesquisas (da Ecologia das Paisagens), uma vez que as transformações humanas da paisagem tornaram-se preponderantes diante dos processos naturais. Os objetos não são mais estáticos. As estruturas que suportam os aspectos dinâmicos de uma paisagem não são estáticas. Apenas apresentam ciclos mais longos que os aspectos que estão sendo estudados (MARTINS et al., 2004, p. 16).

Os autores supracitados concordam sobre a noção de totalidade do espaço geográfico, onde tempo e espaço são indissociáveis. Além disso, concordam que os processos internos da paisagem são formados por diversos elementos, compostos por fatores ambientais (geologia, geomorfologia, clima, solos, vegetação, fauna e intervenções antrópicas).

Podemos elaborar tal afirmação com o seguinte exemplo, ilustrado na Figura 1: uma paisagem P1 se transforma em paisagem P2 dentro de um tempo t1 por meio de seus processos internos $\alpha 1$, posteriormente, $\mathrm{P} 2$ se transforma em $\mathrm{P} 3$ dentro de um tempo t 2 por meio 
de seus processos internos $\alpha 2$, e assim por diante até $\mathrm{Pn}$, dentro de um tempo tn por meio de processos $\alpha \mathrm{n}$, onde a totalidade destes processos formam o espaço geográfico.

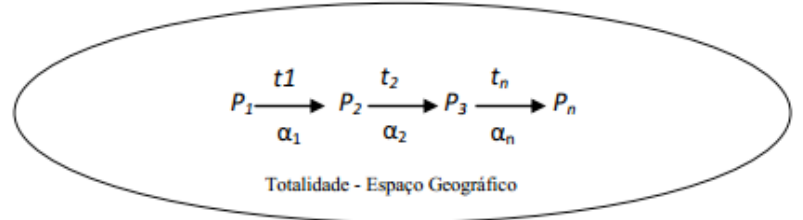

Figura 1 - Perfil esquemático demonstrando como a paisagem se insere dentro da totalidade do espaço geográfico

Assim, podemos visualizar os feixes de vetores colocados por Santos (1996), as funções que cada elemento da paisagem possui, e, quando estas se transformam, a paisagem também se transforma. Maximiano (2004) coloca que estas transformações ocorrem pelo caráter dinâmico dos elementos da paisagem.

Por fim, Martins et al. (2004) sugere a noção de temporalidade, convergindo com as ideias de Santos (1996) de que "a paisagem é um conjunto de formas em um dado momento", porém, para chegar a este momento, ocorreram processos dinâmicos que moldaram a paisagem.

Assim, pode-se afirmar que os padrões da paisagem surgem a partir de diversos processos e respostas entre seus elementos, onde estes atuam em dinâmicas espaciais e temporais distintos envolvendo sua agregação e classificação em entidades ecologicamente interpretáveis (BOLLINGER, 2005).

\subsection{Paisagem e Sistemas}

No geral, as diversas abordagens científicas buscam compreender o funcionamento de um sistema a partir do comportamento de entrada e saída de matéria e energia. Assim, são estudados os fenômenos que ocorrem entre o sistema e o seu meio circundante, ou seja, o estado de um sistema é como ele se apresenta externamente, como, por exemplo, na abordagem da termodinâmica (MARTINS et al., 2004).

É importante lembrar também, dentro deste contexto, a noção definida por Faissol (1973) de que os sistemas são formados por:

- Um conjunto de elementos identificados aos quais atribuímos ou percebemos características não necessariamente similares;

- Um conjunto de relações entre as características
- atributos destes elementos objetivos;

- Um conjunto de relações entre este conjunto de elementos com seu ambiente externo.

Conforme Christofoletti (2004) pode-se considerar dois tipos de sistemas: os sistemas simples ou sistema linear, onde "os componentes são relacionados conjuntamente e agindo um sobre os outros conforme determinadas leis"; e os sistemas dinâmicos complexos definidos como "um conjunto de grande quantidade de elementos interligados, com capacidade de trocar informações com seu entorno condicionante, possuindo também a capacidade de adaptar sua estrutura interna como sendo consequências ligadas a tais interações".

A primeira lei da termodinâmica - Lei de Conservação de Energia - diz que um sistema, quando sofre transformação, gera implicações nos fluxos de matéria e energia. Já a segunda lei da termodinâmica - lei da Entropia - regula tais transformações, ao assegurar que a energia e, em alguns casos, parte da matéria transformada não retorne ao sistema, ou seja, alguns impactos ambientais podem provocar alterações na paisagem de forma que seu estado original não pode ser restaurado por meios naturais

Conforme Martins et al. (2004), os fatores ambientais que formam os elementos da paisagem possuem propriedades emergentes que, quando relacionadas entre si, não são apenas a soma de suas partes, dado que possuem processos e dinâmicas distintos. Sendo que, estes últimos são os indicadores primários para o funcionamento de sistemas ambientais, em que a compreensão de seus ciclos individuais indica como os mesmos atuam e como se inter-relacionam na paisagem em duas escalas diferentes: a escala temporal e a escala espacial.

A primeira se mostra nos ciclos de formação destes fatores, na seguinte ordem: rocha, clima, formas de relevo, solos e organismos. Já na segunda escala, os fatores são relacionados de forma hierárquica, onde uma unidade homogênea possui diversas unidades homogêneas dos fatores posicionados em hierarquia inferior - por exemplo, uma única litologia apresenta diferentes formas de relevo; uma única forma de relevo pode comportar diferentes tipos de solo, etc. (MARTINS et al., 2004). Estas escalas são demonstradas na Figura 2.

Além da paisagem natural, formada pelos elementos descritos na Figura 2, existe a paisagem cultural. Stigliano et al. (2011) define paisagem cultural como a relação entre uma comunidade, abrangendo determinadas 
preferências culturais, e as características naturais da paisagem. Nesse sentido, pode ser analisada tanto como um sistema físico como um sistema econômico por meio da entrada e saída de energia e/ ou capital, por meio da relação entre as atividades antrópicas e os fatores ambientais da paisagem. Tendo como base a taxa de importação e exportação de energia, a paisagem cultural pode ser dividida em local, regional e globalizada, conforme mostra a Tabela 1 (TAPPEINER et al., 1998; MARTINS et al., 2004; BENDER et al., 2005; MUELLER, 2007).

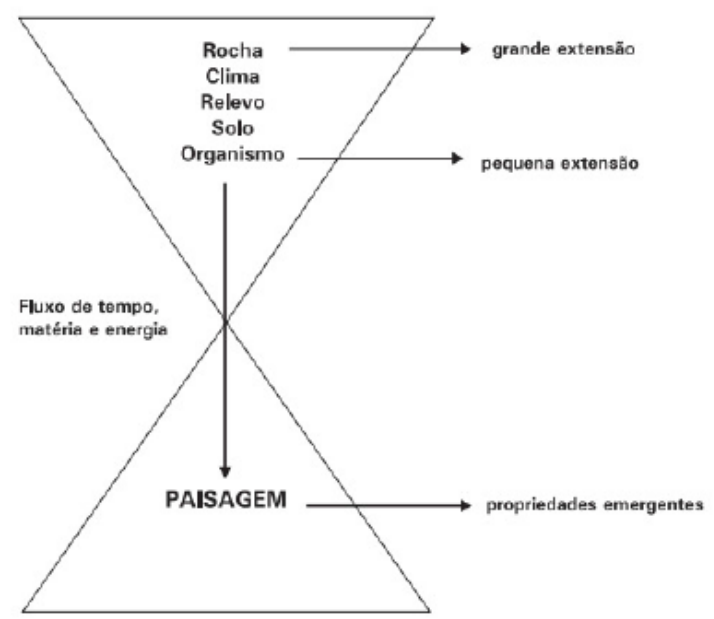

Figura 2 - Principais relações entre os elementos formadores da paisagem, representado por ampulheta (Fonte: Martins et al., 2004)

Além da paisagem natural, formada pelos elementos descritos na Figura 2, existe a paisagem cultural. Stigliano et al. (2011) define paisagem cultural como a relação entre uma comunidade, abrangendo determinadas preferências culturais, e as características naturais da paisagem. Nesse sentido, pode ser analisada tanto como um sistema físico como um sistema econômico por meio da entrada e saída de energia e/ ou capital, por meio da relação entre as atividades antrópicas e os fatores ambientais da paisagem. Tendo como base a taxa de importação e exportação de energia, a paisagem cultural pode ser dividida em local, regional e globalizada, conforme mostra a Tabela 1 (TAPPEINER et al., 1998; MARTINS et al., 2004; BENDER et al., 2005; MUELLER, 2007).

Nesse sentido, a compreensão de como os fluxos de energia afetam a paisagem possibilitaria uma melhor compreensão dos fatores econômicos ambientais envolvidos. Esses fatores, que permeiam questões energéticas, urbanas, ambientais, econômicas, variam em magnitude e intensidade conforme a escala de análise utilizada, em que o intercâmbio de fluxos energéticos da paisagem aumentam gradativamente até chegarem à escala global.
Por fim, chama-se a atenção para as paisagens notáveis, cuja proteção é regulamentada pela Lei Complementar $n^{\circ}$ 140, de 8 de Dezembro de 2011, que possuem grande importância, uma vez que possui, potencial turístico e científico, tais como áreas tombadas, sítios arqueológicos, arquipélagos, paisagens de notável beleza estética, etc. Estas áreas costumam receber um grande número de turistas, necessitam de estudos constantes em relação à sua conservação para que não haja redução de seu valor de uso ou de existência (Su et. al., 2012).

Tabela 1 - Classificação das diversas paisagens culturais

\begin{tabular}{|c|c|c|c|}
\hline $\begin{array}{l}\text { Paisagem } \\
\text { Cultural }\end{array}$ & Descrição & $\begin{array}{c}\text { Nível } \\
\text { tecnológico }\end{array}$ & $\begin{array}{c}\text { Taxa de } \\
\text { importação } \\
e \\
\text { exportação } \\
\text { de energia e } \\
\text { matéria }\end{array}$ \\
\hline Local & $\begin{array}{l}\text { - Produto de longa interação do } \\
\text { homem com o ambiente; } \\
\text { - Possui tendência no equilíbrio } \\
\text { no balanço de matéria e } \\
\text { energia; } \\
\text { - Tendência de ser sustentável } \\
\text { no longo prazo. }\end{array}$ & $\begin{array}{l}\text { Tecnologia que } \\
\text { não depende da } \\
\text { utilização externa } \\
\text { à paisagem }\end{array}$ & Baixa \\
\hline Regional & $\begin{array}{l}\text { - Antecede a tendência de } \\
\text { globalização; } \\
\text { - Fluxos ocorrem entre os centros } \\
\text { urbanos e meio rural; } \\
\text { - O intercâmbio entre regiões } \\
\text { aumenta, de forma progressiva, } \\
\text { até chegar a nível global. }\end{array}$ & & \\
\hline Globalizada & 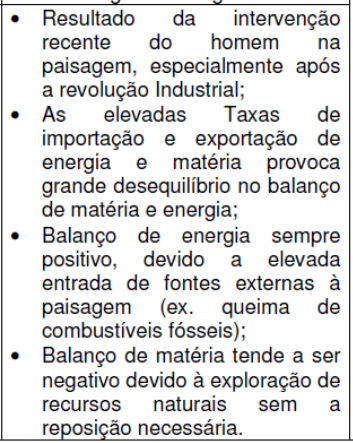 & \begin{tabular}{lr} 
Tecnologia & que \\
depende & da \\
entrada & de \\
energia externa \\
\multicolumn{2}{l}{ ao sistema. }
\end{tabular} & Elevada \\
\hline
\end{tabular}

Fonte: Adaptado de Martins et al. (2004).

\section{ECONOMIA AMBIENTAL}

\subsection{Vertentes da Economia Ambiental}

A economia ambiental se propõe a apresentar soluções de atividades potencialmente poluidoras ou que possam provocar impactos ambientais a partir da aplicação de instrumentos econômicos, estabelecendo soluções econômicas para o gerenciamento ambiental em conjunto com instrumentos jurídicos (NETO e PETERS, 2005). Nesse contexto, a economia ambiental se divide em duas principais vertentes: a economia ambiental neoclássica e a economia ecológica.

A economia ambiental neoclássica possui o seu foco nos problemas ambientais de economias de mercado, com 
base em epistemologia mecanicista, considerando, portanto, um meio ambiente neutro e passivo, onde os impactos ambientais provocados pelo sistema econômico podem ser revertidos. Nesse sentido, esta vertente considera a existência de uma poluição ótima que representa o equilíbrio entre a satisfação do indivíduo perante os benefícios da produção e consumo de determinado bem ou serviço com o mal-estar provocado por estes (MUELLER, 2007).

Como exemplo, Barbier (1998) argumenta que, do ponto de vista econômico, a conservação do solo implica em criar um determinado "estoque" para uso futuro. Por outro lado, um fazendeiro pode escolher intensificar a produção, aumentando, dessa maneira, a pressão sobre o recurso ao custo de maiores taxas de erosão, provocando um esgotamento do recurso e inviabilizando o uso futuro. Neste contexto, op. cit, do ponto de vista econômico, a conservação significa redistribuição de determinado recurso em taxas de uso, visando uma ação futura, enquanto o termo esgotamento significa a redistribuição dos recursos para um uso no tempo presente. Assim, dentro dessa abordagem econômica, o manejo da erosão não deve ter o objetivo de anular os processos erosivos ou até mesmo atingir taxas de erosão ideais, mas deve buscar uma situação em que os benefícios marginais para a conservação do solo sejam iguais aos seus custos.

Já a economia ecológica considera que o sistema econômico provoca alterações, por vezes irreversíveis, ao interagir com os elementos da paisagem. Rejeitando assim, a ideia de que o meio ambiente é passivo, com capacidade ilimitada de fornecer recursos naturais e absorver os resíduos e efluentes gerados pelas atividades do sistema econômico, e, mesmo considerando a resiliência do meio ambiente, esta pode vir a ser comprometida dependendo do tamanho do impacto. Assim, esta vertente do pensamento considera o sistema econômico como uma entidade dotada de vida, que troca matéria e energia com seu meio externo, onde os limites do sistema econômico assim como a natureza de seus impactos merecem destaque (MUELLER, 2007). Por fim, esta vertente busca a definição desses limites, dentro dos princípios da precaução $^{3}$, para a produção e consumo total de bens e serviços ambientais, onde, com este conhecimento, os incentivos econômicos através do mercado podem atuar de maneira significativa na alocação do consumo desses bens e serviços (ROMEIRO, 2003).

\subsection{Técnicas de Valoração Ambiental}

Conforme Ortiz (2003), todo recurso ambiental possui um valor intrínseco, ou seja, o seu valor próprio, interior, inerente ou peculiar, que reflete seu direito de existência e interesses de espécies de fauna, flora e elementos abióticos. Porém, op. cit. que, apesar da existência de métodos para determinar o valor intrínseco dos recursos naturais, o valor econômico destes recursos é aquele diretamente relacionado ao bem-estar social. Em relação à valoração econômica, o autor coloca que:

O principal objetivo da valoração econômica ambiental é esti-
mar os custos sociais de se usar recursos ambientais escassos
ou, ainda, incorporar os benefícios sociais advindos do uso
desses recursos. Os economistas estimam valores ambientais
em termos monetários de maneira a tornar esse valor compa-
rável com outros valores de mercado, de forma a permitir a
tomada de decisões envolvendo recursos ambientais. Ou seja, o
que desejamos é a inclusão dos benefícios (e custos) ambientais
na análise de custo/ benefício envolvendo recursos ambientais.
Dessa forma, a valoração econômica ambiental é fundamental
para a gestão de recursos ambientais, bem como para a tomada
de decisões que envolvam projetos de grande impacto ambien-
tal. Além disso, permite inserir de forma mais realista, o meio
ambiente nas estratégias de desenvolvimento econômico, sejam
estas locais, regionais ou nacionais (ORTIZ, 2003, p. 82).

As técnicas de valoração se dividem em métodos indiretos, diretos, e a análise custo-benefício. Os primeiros são os métodos que se baseiam diretamente nos preços e valores de mercado ou em alterações na produção provocadas por determinado impacto ambiental, além disso, buscam estimar o valor econômico do recurso natural com base nas mudanças provocadas no valor de bens complementares e/ ou bens substitutos. Os métodos diretos são aqueles que, tendo por base os valores de mercado, buscam inferir as preferências individuais por bens ou serviços ambientais a partir de aplicação de questionários (ORTIZ, 2003; MUELLER, 2007). Por fim, a análise custo-benefício é a técnica aplicada quando determinados elementos de um projeto e seus impactos envolvem variáveis cujo valor não pode ser traduzido ou não possui preço de mercado, pautada principalmente no critério de eficiência de Pareto ${ }^{4}$ (MUELLER, 2007).

A Tabela 2 mostra exemplos das principais técnicas de valoração econômica, sendo importante destacar que não é objetivo deste trabalho discorrer sobre cada técnica ou discutir a sua validade e implicações éticas. Porém, é possível notar que, em todas elas existem elementos geográficos que podem acabar se tornando secundárias dentro de uma análise econômica, tais como: impactos físicos, uso do solo, condições ambientais, habitats, alteração da paisagem, entre outros.

Quando aplicamos os conceitos geográficos discutidos anteriormente, podemos visualizar de forma mais clara a afirmação de Constanza et al. (1997), de que o exercício para estimar o valor de serviços ambientais consiste em de- 
terminar que sutis mudanças possam provocar no bem-estar humano.

\section{ESPAÇO, PAISAGEM E ECONOMIA AMBIEN-} TAL

A configuração da paisagem, com seus atributos espaciais e distribuição de seus elementos, são influenciados pela sua forma e como seu planejamento é feito (HEIDE et al., 2008). Nesse sentido, para que a estimativa do valor econômico de um recurso natural seja mais eficiente, é preciso analisar a sua dimensão espacial e temporal, evitando que ele não seja analisado apenas como um bem econômico puro, mas sim como um bem que faz parte do espaço e da paisagem de determinada área, incorporando, dessa maneira, novas variáveis aos modelos econômicos existentes, como, por exemplo, carga de sedimentos, erosão, pluviosidade, fragmentação de vegetação, etc. (CHAVES, 2011).

Tabela 2 - Variáveis Utilizadas pelas Diferentes Técnicas de Valoração

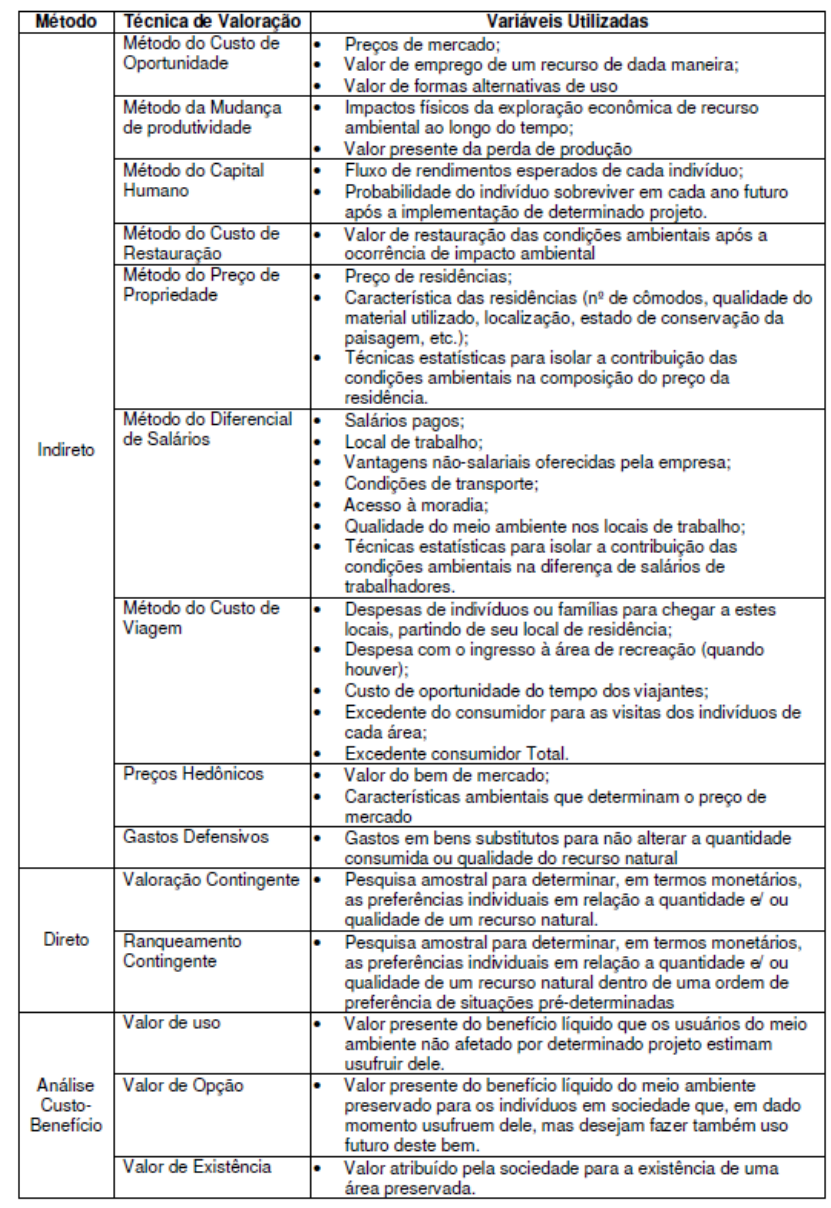

Fonte: Adaptado de Ortiz (2003) e Mueller (2007).
Barbier (1994) afirma que a valoração de um ambiente significa dar valor às características do sistema. Assim, qualquer sistema, seja natural ou antrópico, pode ser caracterizado dentro de três conceitos-chave: estoque, fluxo, e organização desses estoques e fluxos. Essas três características possuem equivalência tanto na paisagem ${ }^{5}$ - componentes estruturais, funções ambientais, e diversidade cultural e paisagística; como na economia - taxação de serviços e atributos $^{6}$ . A Tabela 3 resume esta ideia relacionando os aspectos da paisagem e sistema econômico.

Assim, a avaliação ecológica é utilizada em diversas situações quando se trata do planejamento de paisagens, uso do solo e conservação. Em escalas regionais, as técnicas de valoração são utilizadas para estimar o valor relativo de diferentes localizações dentro de uma determinada área. Em alguns estudos, o resultado da avaliação ecológica é apenas um dos diversos dados de entrada para elaborar planos de uso e conservação do solo, ou para determinar a importância de uma determinada área (WHATERN et al., 1986).

Tabela 3 - Características de Sistemas Gerais, Sistema da Paisagem e Sistema Econômico

\begin{tabular}{|c|c|c|}
\hline $\begin{array}{c}\text { Característica } \\
\text { Geral do } \\
\text { Sistema }\end{array}$ & $\begin{array}{c}\text { Características do } \\
\text { Sistema da } \\
\text { Paisagem }\end{array}$ & $\begin{array}{c}\text { Características do } \\
\text { Sistema } \\
\text { Econômico }\end{array}$ \\
\hline Estoques & $\begin{array}{c}\text { Componentes } \\
\text { Estruturais }\end{array}$ & Taxas \\
\hline Fluxos & Funções ambientais & Serviços \\
\hline Organização & $\begin{array}{c}\text { Diversidade cultural } \\
\text { e paisagística }\end{array}$ & Atributos \\
\hline
\end{tabular}

Fonte: Barbier (1994)

Um exemplo da relação intrínseca entre os conceitos geográficos e a economia ambiental é demonstrado por Mitsch e Gosselink (2000). Neste trabalho realiza-se a valoração econômica de campos pantanosos do centro oeste dos Estados Unidos, considerando os seguintes princípios: 1) os campos pantanosos são um sistema com diversos valores; 2) Os serviços ambientais de maior valor dos campos pantanosos são os que advêm do seu valor de uso e existência; 3) A relação entre as áreas de campos pantanosos e seu valor marginal é complexa; 4) Os valores comerciais possuem limites, enquanto os campos pantanosos oferecem serviços durante a sua existência; 5) A comparação entre o benefício imediato de um uso da paisagem em relação ao benefício em longo prazo da conservação dos campos pantanosos não é adequada; e 6) Os valores são influenciados por fatores culturais e econômicos.

A partir desses seis princípios, op. cit. consideram alguns fenômenos da paisagem e de escala para criar generali- 
zações acerca dos campos pantanosos que tornam a valoração um exercício complexo, que podem ser extrapoladas para outras formas de paisagem.

O primeiro fenômeno é o Princípio da Escala, onde, dependendo da escala ecológica analisada, a complexidade, os benefícios e a sua provável importância, alteram as estimativas de valor (Figura 3).

\section{Complexidade}

Escala

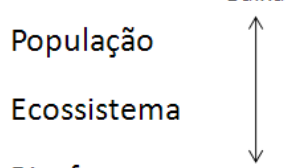

Biosfera
Benefícios

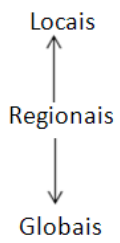

Provável Importância

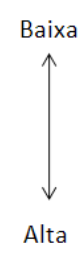

Figura 3 - Complexidade, Escala de Benefícios, e Provável Importância de uma paisagem em diferentes escalas ecológicas (Fonte: MITSCH E GOSSELINK, 2000)

O segundo fenômeno é o Paradoxo do Valor Marginal, em que uma menor disponibilidade de áreas de paisagem natural não implica, necessariamente, um maior valor, considerando que a população humana sobrecarregou as funções de determinada paisagem natural, ou seja, em situações em que existe ausência de vida humana ou situações em que a densidade populacional é tão alta que anula as funções da paisagem, o valor desta é muito baixo ou até mesmo nulo, dado que o valor é atribuído a partir da percepção humana (Figura 4).

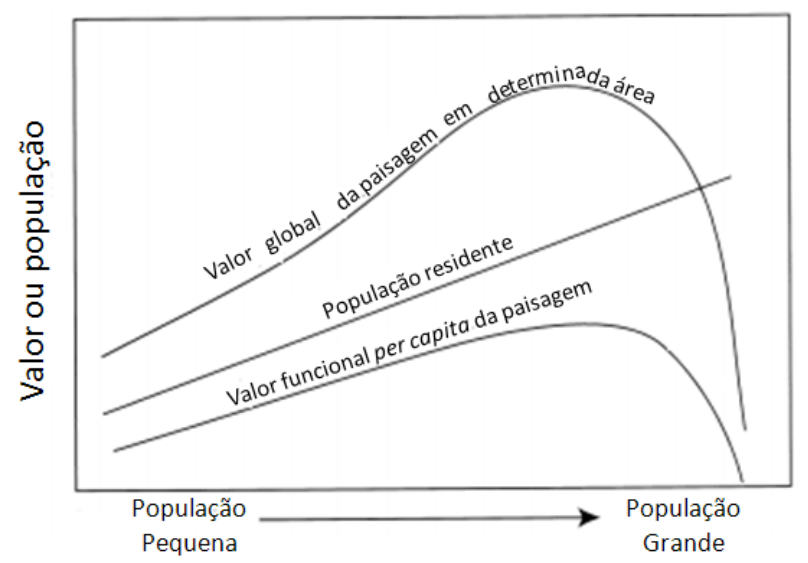

Figura 4 - Valor global de uma porção adicional da paisagem em determinada região em função da população humana próxima. $\mathrm{O}$ valor global é o produto da multiplicação entre a população e o valor funcional per capita. O valor funcional marginal per capita da paisagem inicialmente aumenta conforme a população cresce, dado que a disponibilidade dos recursos da paisagem é reduzida. Porém, a partir do momento em que a população cresce a um certo nível, as funções da paisagem são taxadas com diversos impactos ambientais, reduzindo assim, o valor funcional marginal é reduzido de forma abrupta com o aumento da população a partir deste ponto (Fonte: MITSCH E GOSSELINK, 2000)
Outro fenômeno é o Princípio Hidrogeomórfico, em que o regime hídrico e a movimentação de sedimentos em determinada paisagem possuem funções reguladoras, tais como: áreas de inundação, áreas de acumulação de sedimento, áreas mais propensas à formação de erosão, áreas propensas a formações florestais, arbustivas ou campestres e, a disponibilidade de recursos hídricos à montante e à jusante, entre outros.

Por fim, o fenômeno do Paradoxo da Substituição de Ecossistemas, em que, a análise econômica segue uma lógica na qual diferentes valores são atribuídos a diferentes paisagens, substituindo a paisagem de menor valor por uma de maior valor. Mas como essa substituição é, em muitos casos, fisicamente impossível, dado as características geológicas, climáticas, geomorfológicas e pedológicas de determinada paisagem, esta visão estritamente econômica coloca uma limitação na análise econômica ambiental justamente por não haver uma contextualização espacial de determinado recurso ambiental, como feito em diversos trabalhos econômicos (CONSTANZA et al, 1997; MAY et al., 2003; MUELLER, 2007; FORTES et al., 2010).

Por outro lado, é importante destacar outros trabalhos que incorporam elementos e conceitos geográficos:

- Barbier (1994) faz uma análise de custo-benefício na conservação e alteração de áreas pantanosas em ambientes tropicais a partir do custo de oportunidade advindo com a redução das áreas de campo natural, mostrando que um nível menor de alteração destas seria uma situação mais benéfica. Além disso, o autor discute os limites da função de produção aproximada das características destas áreas que não possuem valor de mercado.

- Geoghegan et al. (1997) desenvolveram um modelo hedônico para explicar a valoração de residências utilizando dados tradicionais para estruturas e loteamento, localização, e características socio-demográficas, e utilizando parâmetros de fragmentação da paisagem utilizando técnicas de geoprocessamento. Um modelo hedonônico é uma forma de modelo estatístico simplificado cujo objetivo é identificar, em determinado ponto do tempo, o locus do equilibrio entre as variações de preço em função das caracteríticas heterogêneas do mercado imobiliário.

- Barbier (1998) considera a taxa de erosão dentro de uma determinada propriedade para estimar o custo da erosão no processo produtivo in-site, deixando implícito que as escolhas feitas pelos produtores para conservar ou não o solo são fortemente influenciadas pela cultura local de produção agrícola; 
- Drake (1999) faz uma análise por método direto, a partir da valoração contingente para estimar o valor da paisagem agrícola na Suécia, utilizando como parâmetros as preferências dos indivíduos e características econômicas, sugerindo algumas políticas para mitigar os problemas identificados, tais como redução de terras agricultáveis, redução de elementos cênicos da paisagem e redução da biodiversidade.

- Heide et al. (2008) apresentou um método para auxiliar o planejamento espacial que combina a eficiência econômica com instrumentos de gestão participativa a partir do conceito de "disposição a pagar" na região norte dos Países Baixos, no distrito de Frisian Lake, aumentando assim, a colaboração mais ativa dos atores envolvidos na dinâmica espacial, de uma maneira a auxiliar os gestores a criar cenários no processo de planejamento e design.

- Constanza et al. (1997) argumentam que os serviços ecossistêmicos representam uma porção considerável do bem-estar humano. Os benefícios oferecidos pelos serviços ecossistêmicos para o bem-estar humano podem variar de serviços simples a serviços mais complexos. Os autores exemplificam uma floresta que oferece desde lenha até solo e umidade, criando microclimas. Porém, ao sugerir que um tipo de paisagem com maior valor econômico deve substituir um de menor valor, os autores não consideraram que esta imposição pode, no longo prazo, provocar diversos impactos ambientais negativos ocasionando, assim, um desequilibrio nos serviços ecossistêmicos prestados pela paisagem.

- Nelson et al. (2009) se utiliza de modelagem espacial baseado em funções de produção para analisar diversos cenários de uso e cobertura da terra, quantificando alterações em diversos serviços ambientais em escala de paisagem para cada cenário e demonstrando as variações que podem ocorrer na valoração dos serviços ambientais em cada um dos cenários simulados.

- Arnold et. al. (2014) realizou estudos de integração do modelo hidrológico SWAT com análises de custo-benefício de diferentes práticas de manejo em diversas bacias dos Estados Unidos. O estudo demonstra que, ao integrar os dois modelos, aumenta-se a confiança em simulações de impactos econômicos pois utiliza dados e conhecimentos gerados pela validação de modelos hidrológicos nas regiões de estudo.

- Fan et. al. (2016) realizaram a integração de serviços ecossistêmicos (nível de água, nutrientes orgânicos e inorgânicos, e retenção de sedimento), utilizando o modelo SWAT, tendo como base alterações de uso do solo e mudanças climáticas em uma bacia hidrográfica localizada na região norte de Japão. Os resultados obtidos pelos autores mostram que é possível realizar políticas de manejo e conservação de serviços ecossistêmicos associado ao desenvolvimento econômico na região.

- Um exemplo prático da aplicação da discussão desse trabalho é o Zoneamento Ecológico Econômico, regulamentado no Brasil pelo Decreto no 4.294, de 10 de Julho de 2002, sendo definido pelo mesmo documento em seus artigos $2^{\circ}$ e $3^{\circ}$ como "instrumento de organização do território" tendo como objetivo "organizar, de forma vinculada, as decisões dos agentes públicos e privados quanto a planos, programas, projetos e atividades que, direta ou indiretamente, utilizem recursos naturais, assegurando a manutenção do capital e serviços ambientais dos ecossistemas" levando em conta as características dos diversos ecossistemas existentes no território nacional. Para detalhes sobre estudos e discussões acerca do ZEE, ver Ab’Sáber (1989); Crepani et. al. (1996); Acselrad, (2000); Crepani et. al. (2001); STEINBERGER (2006); VASCONCELOS et. al. (2013) entre diversos outros.

Percebe-se, pelos trabalhos citados acima, que as ferramentas de geoprocessamento atuam como plataforma de integração de modelos ambientais e econômicos, reduzindo a utilização de modelos conceituais e/ ou generalistas, uma vez que esta ferramenta permite a espacialização de dados empíricos, geralmente carentes em análises de valoração ambiental (CHAVES, 2011; ANDRADE e ROMEIRO, 2013). $\mathrm{Na}$ Tabela 4 são demonstrados alguns exemplos em que cada um dos conceitos apresentados neste trabalho podem ser aplicados.

Por fim, Gómez-Baggethun et al. (2010), demonstram, a partir de uma análise do desenvolvimento do conceito de serviços ambientais, que o foco da valoração monetária e regimes de pagamento influenciaram para atrair apoio político para ações conservacionistas. Porém, contribuiu para a comoditização de diversos serviços ambientais reforçando assim os paradigmas da economia neoclássica e reproduzindo a lógica do mercado na forma de intervenção em problemas ambientais, uma vez que, se o valor recebido não for alto o suficiente para compensar os custos de oportunidade de determinado serviço ambiental, então esta ação, dentro desse paradigma, pode ser considerado ineficiente.

Para contrapor esta visão, a aplicação do conceito de espaço geográfico - como um conjunto de objetos e ações (SANTOS, 1996) -, trazendo a noção de totalidade de processos, em que tempo e espaço são indissociáveis, associado à noção de como os elementos da paisagem interagem entre si, e como a paisagem se transforma, contribui para tornar 
esta análise mais objetiva, com melhores critérios de análise, tendo como base as diferentes paisagens em diversos espaços geográficos formados ao longo do tempo. Assim, discussões carentes de dados empíricos, tal como a valoração de serviços ambientais, (DE GROOT et al., 2010; ANDRADE e ROMEIRO, 2013), teria um aporte de conceitos e tipologias para os serviços, valores e benefícios gerados por ações conservacionistas.

Tabela 4 - Exemplos de aplicação dos conceitos geográficos

\begin{tabular}{|c|c|}
\hline Conceito & Aplicação \\
\hline \multirow{4}{*}{ Paisagem Natural } & $\begin{array}{l}\text { Análise de erosăo laminar em áreas de agricultura para estimar } \\
\text { seus custos internos e externos na produçăao agricola. } \\
\text { Análise de cobertura vegetal em parques urbanos e seu entorno } \\
\text { e como a valoraçáa imobiliária ocorre em torno desta área com } \\
\text { base nas áreas de preservaçăo permanente - APP. }\end{array}$ \\
\hline & $\begin{array}{l}\text { Correlaçăo entre variaçōes meteorológicas e eventuais } \\
\text { mudanças climáticas afetam produçăo de alimentos, energia, e } \\
\text { abastecimento de água. }\end{array}$ \\
\hline & $\begin{array}{l}\text { Análise de regime hidrológico para auxiliar nos cálculos } \\
\text { referentes a taxas de uso de água e esgoto em cidades durante } \\
\text { periodos de escassez de chuvas. }\end{array}$ \\
\hline & $\begin{array}{l}\text { Determinaçăo do valor de uso e existência de determinado bioma } \\
\text { com base em suas caracteristicas ambientais, com base nos } \\
\text { critérios de análises propostos por Mitsch e Gosselink (2000). }\end{array}$ \\
\hline \multirow{3}{*}{ Paisagem Cultural } & $\begin{array}{l}\text { Análise de correlaçăo da taxa de crescimento urbano e } \\
\text { demográfico com demanda de água e energia elétrica de } \\
\text { reservatórios para previsão de variaçōes nas taxas de uso do } \\
\text { recurso. }\end{array}$ \\
\hline & $\begin{array}{l}\text { Correlaçăo entre utilização de recursos tecnológicos e aumento } \\
\text { de produtividade agricola, tendo como base caracteristicas do } \\
\text { solo, relevo, clima e seus impactos sobre preços de commodities. } \\
\text { Correlaçăo de variaçāes meteorológicas e prováveis mudanças } \\
\text { climáticas e aumento de doenças transmitidas por vetores. }\end{array}$ \\
\hline & $\begin{array}{l}\text { Relacionar o nivel de fragmentacáa da cobertura vegetal com } \\
\text { crescimento de áreas de agricultura e/ ou urbanas e como os } \\
\text { impactos sobre serviços ambientais afetam a economia em } \\
\text { diferentes escalas. }\end{array}$ \\
\hline Paisagem Notável & $\begin{array}{l}\text { Com base em séries históricas da dinâmica ambiental do local, } \\
\text { determinar a taxa de uso de áreas de locais como unidades de } \\
\text { conservaçăo, dentro do que estabelece a legislaçăo pertinente. } \\
\text { Com base em análises de crescimento demográfico, e estudos } \\
\text { de crescimento ou redução do turismo em áreas tombadas, } \\
\text { determinar onivel de investimento necessário para conservaçăa } \\
\text { dessas áreas. }\end{array}$ \\
\hline Espaço Geográfico & 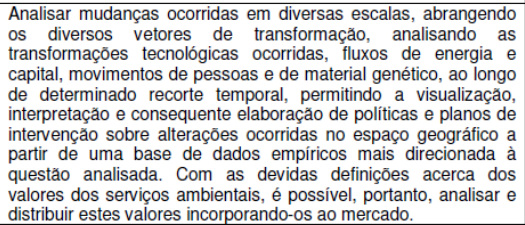 \\
\hline
\end{tabular}

\section{CONSIDERAÇÕES FINAIS}

Neste trabalho foi proposta uma aplicação dos conceitos geográficos para a economia ambiental, falta precisão das técnicas de valoração ambiental para que se possa chegar aos valores econômicos do meio ambiente.

Assim, foi utilizado, por ter um caráter mais geral, o conceito de espaço como um conjunto de objetos e ações, como os elementos da paisagem interagem entre si e como a paisagem se transforma, dentro da lógica dos sistemas, diferenciando a paisagem natural e cultural.

A economia ambiental apresenta duas principais vertentes: economia ambiental neoclássica e a economia ecológica, possuindo diversas técnicas e métodos de valoração ambiental. Porém, alguns autores, ao ignorar as características da paisagem, considerando o espaço como sendo homogêneo, acabam caindo no Paradoxo da Substituição de Ecossistemas, onde a análise econômica direta pode sugerir que um ecossistema que possua maior valor seja substituído por um de menor valor, ignorando assim, que o espaço geográfico é a totalidade dos processos.

Retomando a ideia da Figura 1, em que as paisagens se formam por meio de processos diversos em tempos diversos, pode-se afirmar, perante o exposto, que as atividades econômicas contribuem significativamente para a alteração e criação de novas paisagens, contribuindo para a formação da totalidade do espaço. Em contrapartida, os elementos que compõem a paisagem e consequentemente, a totalidade do espaço, conforme demonstrado, são variáveis importantes na composição do valor econômico ambiental, que devem ser considerados em seus diferentes contextos espaciais para que a valoração seja mais próxima da realidade. Além disso, verifica-se que os diversos autores analisados seguem tanto a vertente da economia ambiental neoclássica como a vertente da economia ecológica e que os conceitos geográficos apresentados têm a contribuir para a ciência econômica ambiental como um todo, independente da vertente escolhida para a análise.

Assim, pode-se concluir que os conceitos geográficos fornecem uma gama de ferramentas teóricas e práticas a serem incorporadas aos modelos da economia ambiental, uma vez que, ao se ter um conhecimento maior dos processos que envolvem as transformações da paisagem provocadas pelas atividades econômicas, é possível desenvolver estes modelos, incorporando novas variáveis e aumentando a sua precisão, tanto do ponto de vista quantitativo como do ponto de vista qualitativo.

\section{REFERÊNCIAS BIBLIOGRÁFICAS}

AB'SÁBER, A. "Zoneamento Ecológico e Econômico da Amazônia: Questões de Escala e Método". Estudo Avançados, São Paulo, 3, 1989,pp. 4-20.

ACSELRAD, H. “'Zoneamento Ecológico-econômico- entre a ordem visual e o mercado-mundo". In: XII Encontro Nacional de Estudos Populacionais, 2000, Caxambu-MG. XII Encontro Nacional de Estudos Populacionais. Anais... 2000, pp. 1-28. Disponível em: <http://www.abep.nepo. unicamp.br/docs/anais/pdf/2000/todos/ambt25_2. pdf>. Acessado em: 09/08/2015.

ANDRADE, D.C.; ROMEIRO, A.R. "Valoração de serviços ecossistêmicos: por que e como avançar?". Sustentabilidade em Debate, Brasilia, v. 4, nº 1, 2013, p. 43-58. 
Arnold, B. C. "Pareto Distribution". Wiley StatsRef: Statistics Reference Online, 2015, p. 1-10. Disponível em: <http://onlinelibrary.wiley.com/ doi/10.1002/9781118445112.stat01100.pub2/pdf $>$. Acessado em: 20/10/2016.

ARNOLD, J.G.; HARMEL, D.; JOHNSON, M.V.V.; BINGNER, R.; STRICKLAND, T.C.; WALBRIDGE, M.; CHINNASAMY, S.; DILUZIO, M.; WANG, X. "Impacts of the Agricultural Service Research Service Watershed Assessment studies on the conservation effects assessment Project Cropland National Assessment". Journal of Soil and Water Conservation, 69 (5), 2014, 137A-144A.

BARBIER, E.B. "Valuing Environmental Functions: Tropical Wetlands. In: Land Economics”. Vol. 70, n 2., 1994, pp. 155-173. Disponível em: http://www.jstor.org/stable/3146319 . Acessado em: 24/09/2012

"The Economics of Soil Erosion: Theory, Methodology and Examples". In: BARBIER, E.B. The Economics of Environment and Development: Selected Essays, Edward Elgar, Cheltenham, UK, 1998, pp. 281-307.

BENDER, O.; BOEHMER, H.J.; JENS, D.; SCHUMACHER, K.P. "Using GIS to analyse long-term cultural landscape change in Southern Germany". In: Landscape and Urban Planning, Elsevier, n ${ }^{\circ} 70,2005$, p. 111-125.

BENNET, H.H.. "Some Aspects of Soil Erosion as a National Problem". Soil Science Society of American Journal, v. B10, n. 1-2, 1929, p. 55-74.

BOLLINGER, J. "Simulating complex landscapes with a generic model: Sensitivity to qualitative and quantitative classifications". Ecological Complexity, no 2, 2005,p. 131 149.

CARLOS, A.F.A. A condição espacial. São Paulo. Contexto, 2011, 157p.

CHAVES, T.A. Análise do Custo Econômico da Erosão em uma Bacia Hidrográfica Ocupada por Agricultura - Um Estudo de Caso na Bacia do Rio Jardim-DF. 2011, Dissertação de Mestrado em Geografia. Universidade de Brasilia, Instituto de Ciências Humanas, Departamento de Geografia, 86p.

COSTANZA, R.; D'ARGE, R.; DE GROOT, R.; FAR-
BER, S.; GRASSO, M. HANNON, B.; LIMBURG, K. NAEEM, S.; O’NEILL, R.V.; PARUELO, J.; RASKIN, R.G.; SUTTON, P. VAN DEN BELT, M. "The value of the world's ecosystem services and natural capital'. In: Nature, vol. 387, nº1, 1997, p. $253-260$.

CHRISTOFOLETTI, A. L. H. "Sistemas Dinâmicos: As abordagens da Teoria do Caos e da Geometria Fractal em Geografia". In: VITTE, A.C. \& GUERRA, A.J.T. Reflexões sobre a geografia física no Brasil. Rio de Janeiro, Bertrand Brasil, 2004, p. 89-110.

CREPANI,E.; MEDEIROS,J.S.; HERNANDEZ FILHO, P.; FLORENZANO, T. G.; DUARTE, V. BARBOSA, C.C.F. "Sensoriamento Remoto e Geoprocessamento Aplicados ao Zoneamento Ecológico-Econômico e ao Ordenamento Territorial". São José dos Campos, INPE, Ministério da Ciência e Tecnologia, junho de 2001, 103.p.. Disponível em: <www.dsr.inpe.br/laf/sap/artigos/ CrepaneEtAl.pdf> . Acessado em: 09/08/2015.

DRAKE, L. "The Swedish agricultural landscape - economic characteristics, valuations and policy options". In: International Journal of Social Economics, vol. 26, $\mathrm{n}^{\circ} 7-9$, 1999, pp. 1042-1062.

DE GROOT, R.S.; ALKEMADE, R.; BRAAT, L.; HEIN, L.; WILLEMEN, L. "Challenges in integrating the concept of ecosystem services and values in landscape planning, management and decision making". In: Ecological Complexity, no 7,2010 , p. 260-272.

FAISSOL, S. "Problemas Geográficos brasileiros: análises quantitativas”. IBGE, 1973, 271p.

FAN, M.; SHIBATA, H.; WANG, Q. “Optimal conservation planning of multiple hydrological ecosystem services under land use and climate chances in Teshio river watershed, northernmost of Japan" In: Ecological Indicators, vol. 62, 2016, p. 1-13.

FISHER, B.; TURNER, R.K.; MORLING, P. "Defining and classifying ecosystem services for decision making". In: Ecological Economics, $n^{\circ}$ 68, 2009, p. 643-653.

FORTES, M.Z.; BARBOSA, M.V.; NASCIMENTO, R.C.; CARVALHO, J.T.; ALBUQUERQUE, C.J. "Análise de Viabilidade Técnico-Econômica para Erradicação de Árvores sob Linhas de Distribuição". In: Revista Brasileira 
de Energia, vol. 16, nº1, 2010, pp. 93-106.

GEOGHEGAN, J.; WAINGER, L.A.; BOCKSTAEL, N.E. "Spatial landscape in a hedonic framework: an ecological economics analysis using GIS". In: Ecological Economics, $n^{\circ} 23$, p.251-264, 1997.

GÓMEZ-BAGGETHUN, E; DE GROOT, R.; LOMAS, P. L.; MONTES, C. "The history of ecosystem services in economic theory and practice: From early notions to markets and payment schemes". In: Econolical Economics, no 69. 2010, p. 1209-1218.

HARTSHORNE, R. "Perspective on the Nature of Geography”. Association of American Geographers, Monograph Series, No. 1. Chicago: Rand McNally, 1959, 201p.

HARVEY, D. O enigma do capital e as crises do capitalismo. São Paulo: Boitempo, 2011, 240p.

HEIDE, C.M. van der; BLAEIJ, A.T.; HEIJMAN, W.J.M. "Economic aspects in landscape decision making: a participatory planning tool based on a representative approach". In: 12th Congress of the European Association Economists - EAAE. Proceedings. 2008, p. 1-10.

HOLZER, W. "Paisagem, imaginário, identidade: alternativas para o estudo geográfico". In: ROSENDAHL, Zeny; CORREAA, Roberto Lobato (Org.) Manifestações da cultura no espaço. Rio de Janeiro: Ed. UERJ. 1999, pp. 149168.

LA BLACHE, V. "Os Gêneros de Vida na Geografia Humana. Nossos Clássicos: Geografia Geral”. GEOgraphia, Ano 7, n 13, 2005, pp. 113-130.

MARTINELLI, M. e PEDROTTI, F. "A Cartografia das Unidades de Paisagem: Questões Metodológicas”. Revista do Departamento de Geografia, USP, 14, 2001, p. 39-46.

MARTINS, E.S.; REATTO, A.; CARVALHO JR., O.A.; GUIMARÃES, R.F. "Ecologia da Paisagem: Conceitos e Aplicações Potenciais no Brasil". Documentos Embrapa, $\mathrm{n}^{\mathrm{o}} 121,2004,35 \mathrm{p}$.

MAXIMIANO, L. A. “Considerações sobre o conceito de paisagem". Revista RA'e GA, Curitiba, Editora UFPR, n ${ }^{\circ}$ 8, 2004, p. 83-91,

MAY, P.H.; LUSTOSA, M.C.; VINHA, V. Economia do
Meio Ambiente: Teoria e prática. Rio de janeiro: Elsevier, $5^{\mathrm{a}}$ impressão, $318 \mathrm{p}$

MITSCH, W.J.; GOSSELINK, J.G. "The value of wetlands: importance of scale and landscape setting". In: Ecological Economics, no 35, 2000, p. 25-33.

MUELLER, C. C. Os economistas e as relações entre o sistema econômico e o meio ambiente. Brasília: Editora Universidade de Brasília, Finatec, 2007, 562p.

NELSON, E.; MENDONZA, G.; REGETZ, J.; POLASKY, S.; TALLIS, H.; CAMERON, D.R.; CHAN, K.M.; DAILY, G. C.; GOLDSTEIN, J.; KEREIVA, P.M.; LOSDORF, E.; NAIDOO, R.; RICKETS, T.H.; SHAW, M. R. "Modelling multiple ecosystem services, biodiversity conservation, commodity production, and tradeoffs at landscape scales". In: Front Ecol Environ, v. 7, n 1, 2009, p. 4-11.

NETO, R. O.; PETTER, C.O. "A abordagem econômica no contexto da mineração". REM: E. Esc. Minas, Ouro Preto, vol. 58, no 1, 2005, p. 71-75.

ORTIZ, R.A. "Valoração Econômica Ambiental". In: MAY, P.H.; LUSTOSA, M.C.; VINHA, V. (orgs). Economia do Meio Ambiente: Teoria e prática. Rio de janeiro: Elsevier, $5^{\mathrm{a}}$ impressão, 2003, 318 p.

ROCHA, S. A. “Geografia Humanista: História, conceitos e o Uso da paisagem percebida como Perspectiva de Estudo". In: Revista RA'EGA, Curitiba, n. 13, Editora UFPR, 2007, pp. 19-27.

ROMEIRO, A.R. "Economia ou Economia Política da Sustentabilidade". In: MAY, P.H.; LUSTOSA, M.C.; VINHA, V. (Orgs). Economia do Meio Ambiente: Teoria e prática. Rio de janeiro: Elsevier, $5^{a}$ impressão, 2003, 318 p.

SANTOS, M. "A natureza do Espaço. Técnica e tempo. Razão e emoção”. São Paulo: HUCITEC, $4^{\mathrm{a}}$ edição, 1996, 384p.

STEINBERGER, M. "Território, Ambiente e Políticas Públicas Espaciais". Brasília, Paralelo 15 e LGE Editora, 2006,406p.

STIGLIANO, B. V.; RIBEIRO, H.; CESAR, P. A. B. "Paisagem Cultural e Sustentabilidade: Possíveis Conexões e 
Subsídios para Políticas Públicas e Planejamento do Turismo". Revista Turismo em Análise, vol. 22, no 3, 2011, p. 632-650.

SU, S.; XIAO, R.; JIANG, Z.; ZHANG, Y. “Characterizing landscape pattern and ecosystem service value changes for urbanization impacts at an eco-regional scale". In: Applied Geography, Volume 34, 2012, p. 295-305,

TAPPEINER, U.; TASSER, E.; TAPPEINER, G. "Modelling vegetation patterns using natural and anthropogenic influence factors: preliminary experience with a GIS based model applied to an Alpine area”. In: Ecological Modelling, $\mathrm{n}^{\circ} 113,1998$, pp. 225-237.

VASCONCELOS, V. V.; HADAD, R. M.; MARTINS JÚNIOR, P.P. “Zoneamento Ecológico-Econômico - Objetivos e Estratégias da Política Ambiental”. In: Gaia Scientia, 7(1), 2013, p. 119-132.

VEIGA, J.E.; EHLERS, E. 'Diversidade Biológica e Dinamismo Econômico no Meio Rural”. IN: MAY, P.H.; LUSTOSA. M.C.; VINHA, V. (ORGS). Economia do Meio Ambiente: Teoria e prática. Rio de janeiro: Elsevier, $5^{\mathrm{a}}$ impressão, 2003, 318 p

WATHERN, P.; YOUNG, S.N.; BROWN, I.W.; ROBERTS, D.A. "Ecological Evaluation Techniques". In: Landscape Planning, nº 12, 1986, pp. 403-420.

\section{Notas de Fim:}

1- Constanza et al. (1997) consideram capital como um estoque de materiais ou informações que existem em determinado tempo, descrevendo suas categorias como: A) O capital natural é composto pelos elementos do meio ambiente, tais como minerais, ecossistemas, atmosfera, etc.; B) O capital manufaturado consiste no maquinário e edificações, e; C) O Capital humano consiste nos recursos humanos disponíveis.

2- Para uma discussão mais detalhada sobre a evolução do conceito de Espaço Geográfico, ver La Blache (2005); Hartshorne (1959); Santos (1996); Harvey (2011); e Carlos (2011).

3- O princípio da precaução tem como objetivo "tratar de situações em que é necessário considerar legítima a adoção por antecipação de medidas relativas a uma fonte potencial de danos sem esperar que se disponha de certezas científicas quanto às relações de causalidade entre a atividade em questão e o dano temido" (ROMEIRO, 2003 p. 21).

4- O Ótimo de Pareto pode ser definido como uma situação econômica ótima em que um agente econômico pode melhorar a sua si- tuação sem prejudicar outro agente econômico. Para uma discussão mais aprofundada do tema, ver Arnold (2015).

5- Barbier (1994), assim como outros autores (Constanza et al., 1997; Barbier, 1998; Ortiz, 2003; Romeiro, 2003, Mueller, 2007, entre outros), utilizam, em alguns casos, termos como "ecologia", "diversidade biológica", "ambiente", etc., para se referir a elementos e funções da paisagem.

6- Os atributos são definidos como a "diversidade biológica, característica ou herança cultural única, etc., que possuem valor econômico por induzirem atividades econômicas ou por possuir valor por si mesmo" (BARBIER, 1994, p. 156).

\section{Correspondência dos autores:}

\section{Thiago Avelar Chaves}

e-mail: thiagochvs@gmail.com

Osmar Abilio de Carvalho Júnior

e-mail: osmajr@unb.br

Roberto Arnaldo Trancoso Gomes

e-mail: robertogomes@unb.br

Jorge Enoch Furquim Werneck Lima

e-mail: jorge.werneck-lima@embrapa.br

Renato Fontes Guimarães

e-mail: renatofg@unb.br
Artigo recebido em: 06/08/2016

Revisado pelos autores em: 23/09/2016

Aceito para publicação em: 03/11/2016 